\title{
PENGGUNAAN METODE MARKOV CHAIN DALAM PENJADWALAN PERAWATANMESIN UNTUK MEMINIMALKAN BIAYA KERUSAKAN MESIN DAN PERAWATAN MESIN MILL 303 DI PT. STEEL PIPE INDUSTRY OF INDONESIA UNIT 3
}

\author{
Indra Irdianto ${ }^{1}$, Suhartini $^{2}$ \\ email : indrairdianto@gmail.com, suhartini@itats.ac.id \\ Teknik Industri, Fakultas Teknologi Industri, Institut Adhi Tama Surabaya \\ Kampus ITATS Arief Rachman Hakim Surabaya 60117
}

\begin{abstract}
ABSTRAK
PT. Steel Pipe Industry Of Indonesia adalah perusahaan pembuat pipa baja dan pipa baja lapis galvanis yang berdiri sejak 1971 yang berlokasi di Desa Waru Gunung, Kecamatan Karang Pilang, Kota Surabaya. PT. Steel Pipe Industry Of Indonesia memiliki beberapa mesin dalam proses produksinya salah satu mesin yang digunakan yaitu mesin mill untuk membuat pipa. Penelitian ini bertujuan Untuk meminimalkan biaya kerusakan pada mesin mill 303 dan merencanakan perawatan mesin mill 303 sehingga dapat mengurangi biaya pemeliharaan. Metode yang digunakan dalam penelitian ini adalah Markov chain. Metode Markov Chain dapat memprediksi atau meramalkan keadaan masa yang akan datang hanya dengan mengetahui sifat-sifat dari masa lampau dan perhitungan yang digunakan tidak terlalu rumit. Sehingga dapat menjadi solusi untuk melakukan perencanaan penjadwalan dan pemeliharaan mesin Mill 303. Hasil pengolahan yang didapat dengan menggunakan metode markov chain Selisih biaya PM dan CM yang diusulkan ringan adalah Rp 372,937,335 (68\%). Pada kondisi kerusakan sedang adalah Rp 307.124,864 (56\%). Pada kondisi kerusakan berat adalah Rp 471,656,042 (86\%). Pemeliharaan optimal akan didapatkan saat perusahaan melakukan penjadwalan maintenance usulan dengan jangka waktu 12 hari.
\end{abstract}

Kata kunci : Markov Chain, penjadwalan mesin, kerusakan mesin, mesin Mill 303

\section{PENDAHULUAN}

Industri merupakan kegiatan ekonomi yang mengolah bahan mentah menjadi barang yang bermutu tinggi dalam penggunaanya. Pada proses produksi dalam sebuah manufaktur, dimana bahan mentah akan diolah sehingga menghasilkan barang yang bernilai tinggi bagi konsumen. Suatu Industri di Indonesia merupakan hal yang sangat penting dalam salah satu komponen perekonomian.

PT. Steel Pipe Industry of Indonesia Tbk adalah perusahaan dalam bidang pipa baja dimana dalam melakukan proses produksinya banyak menggunakan mesin dan peralatan. Permasalahan yang sering terjadi dalam proses produksi akan berpengaruh terhadap kelancaran pencapaian tujuan perusahaan. Perusahaan mempunyai tujuan proses produksi berjalan lancar maka untuk mencapai tujuan tersebut maka kondisi peralatan dan mesin harus dalam kondisi terjaga dan terpelihara dengan baik. Kondisi mesin dan peralatan yang ada di perusahaan harus terjadwal dalam pemeliharaannya.

PT. Steel Pipe Industry of Indonesia Tbk merupakan perusahaan pembuat pipa baja dan pipa baja lapis galvanis yang berdiri sejak 1971 yang berlokasi di Desa Waru Gunung, Kecamatan
Karang Pilang, Kota Surabaya. Pada awalnya perusahaan ini merupakan perusahaan patungan (Joint Venture) antara Pihak Swasta Indonesia dengan Pihak Jepang yaitu dari Kawasaki Steel Corp. (Indonesia) dengan Citoh \& Co.Ltd (Jepang). Pada tahun 1990, status perusahaan berubah dari perusahaan modal asing menjadi perusahaan modal dalam negeri. Perubahan tersebut diiringi dengan peningkatan kapasitas produksi dari 12.000 ton/tahun menjadi 42.000 ton/tahun..

PT. Steel Pipe Industry of Indonesia Tbk yang merupakan suatu perusahaan manufaktur, bergerak dalam produksi pembuatan pipa baja. Pemeliharaan mesin yang ada di perusahaan pada saat ini tidak dilakukan dengan baik sehingga sering terjadi kerusakan pada mesin, kerusakan yang sering terjadi adalah khususnya mesin cutting yang sering tumpul, selang $H F$ Welding sering bocor dan motor cutoff sering terbakar, sehingga mengganggu proses produksi dan menyebabkan pembengkakan biaya perawatan akibat downtime kerusakan mesin mill 303. Data downtime teknik periode Januari-September 2017, rata-rata Frekuensi downtime HF welding adalah $20.4 \%$ perbulan dibandingkan dengan rata-rata frekuensi downtime Teknik sedangkan rata-rata waktu downtime HF welding adalah $15.2 \%$ perbulan 
dibandingkan dengan rata-rata waktu downtime Teknik. Perusahaan, apabila tidak melakukan penanganan downtime kerusakan mesin yang lebih serius maka akan mengakibatkan presentase frekuensi downtime tinggi sehingga proses produksi akan berjalan tidak lancar dan secara tidak langsung akan mengurangi kapasitas produksi yang sudah di targetkan. Kapasitas yang tidak maksimal akan mengakibatkan produk yang tersedia di pasar akan berkurang sehingga permintaan konsumen tidak bisa terpenuhi.

Dari permasalahan yang sudah dibahas di atas maka metode yang digunakan dalam penelitian ini adalah metode Marko Chain. Metode cocok untuk masalah yang ada di PT. Steel Pipe Industry of Indonesia Tbk. khususnya di bagian produksi. Metode Markov Chain memiliki keunggulan untuk mendapatkan biaya pemeliharaan yang optimal. Sedangkan kekurangan adalah sistem stochastic yang hanya mempunyai karakter bahwa terjadinya suatu state pada suatu saat bergantung pada dan hanya pada state yang bisa di gunakan dengan metode Markov Chain. Pada sistem penjadwalan yang teratur maka proses produksi yang dilakukan akan berjalan lancar dan secara tidak langsung akan berpengaruh pada mendapat biaya sehingga akan mengoptimalkan biaya. Perusahaan harus melakukan penjadwalan mesin Mill 303 secara berkala dan teratur, dengan kegiatan perbaikan, pengontrolan, dan penggantian suku cadang, maka hal ini akan dapat memberikan hasil produksi yang menjanjikan. Permasalahan yang ada di perusahaan adalah perawatan mesin mill 303 dimana pada mesin tersebut pada bagian mesin cutting yang sering tumpul, bagian selang $H F$ Welding sering terjadi kebocoran dan motor cutoff sering terbakar, dari kejadian kerusakan yang terjadi pada mesin akan mengganggu jalannya proses produksi sehingga menyebabkan pembengkakan biaya perawatan akibat downtime kerusakan mesin mill 303.

Berdasarkan permasalahan diatas, maka penelitian ini membahas penjadwalan preventive maintenance yang ada pada PT. Steel Pipe Industry of Indonesia Tbk dan bagaimana meminimalkan biaya kerusakan pada mesin mill 303 dan perencanaan preventive maintenance sehingga dapat mengurangi biaya pemeliharaan.

Penelitian ini bertujuan untuk mengurangi biaya pemeliharaan mesin mill 303 dan penjadwalan preventive maintenance, metode yang digunakan adalah Markov Chain. Kelebihan metode Markov Chain adalah didapatkan biaya pemeliharaan yang optimal dan kelemahannya adalah pada sistem stochastic yang mempunyai karakter terjadinya suatu state bergantung pada state yang bisa di gunakan dengan metode Markov Chain.

\section{METODE PENELITIAN}

Metode penelitian merupakan uraian langkah-langkah penelitian sebagai kerangka pemikiran dalam memecahkan masalah agar penelitian yang dilakukan berjalan secara sistematis dan terarah. Pada bab ini akan dibahas tentang langkah-langkah dalam penelitian ini. Langkah-langkah tersebut akan terbagi menjadi beberapa tahapan. Adapun tahapan-tahapan tersebut adalah sebagai berikut:
1. Tahap Identifikasi
2. Tahap Pengumpulan
3. Tahap Pengolahan Data
4. Tahap Analisa dan Pembahasan
5. Tahap Kesimpulan dan Saran

Berikut ini adalah penjelasan-penjelasan dalam metodologi penelitian yang digunakan dalam penyusunan laporan penelitian ini.

Berikut adalah flowchart dari metodologi penelitian yang dapat dilihat pada gambar 1 dibawah ini.

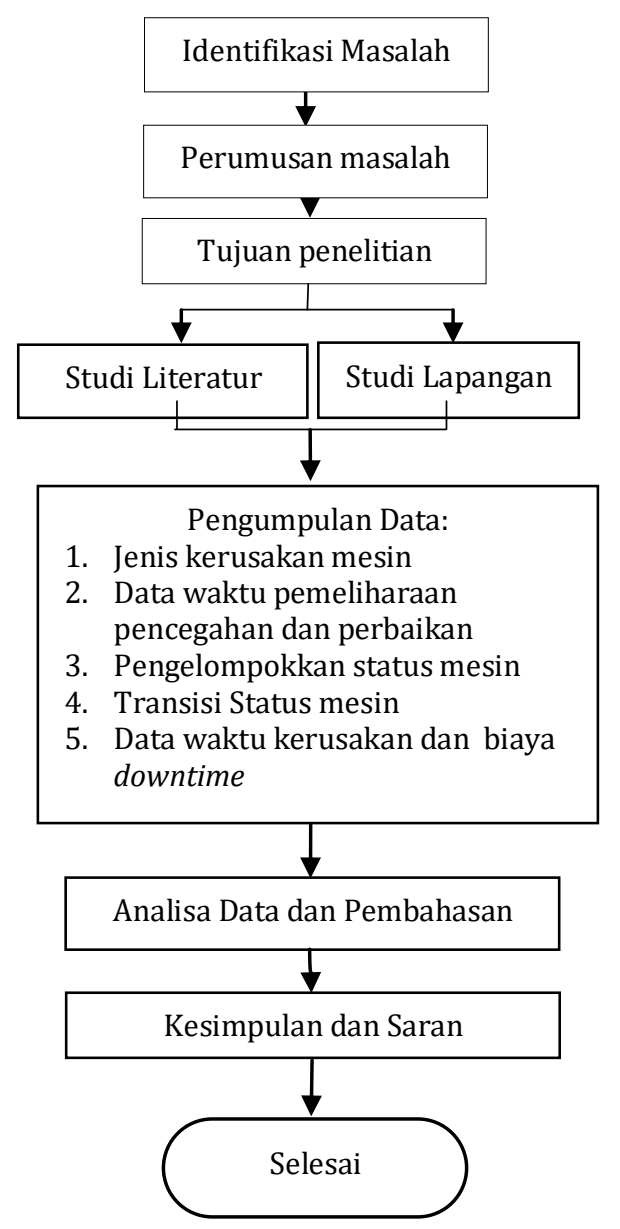

Gambar 1. Flowchart Metode 


\section{Tahap Identifikasi Masalah}

Dalam tahap identifikasi ini adalah tahapan untuk merumuskan suatu masalah sebagai penyelesaiannya yang bertujuan untuk mengidentifikasi latar belakang masalah dibuat penelitian ini, perumusan masalah yang difokuskan pada kecacatan, penetapan tujuan penelitian, menentukan batasan dan asumsi yang nantinya akan digunakan dalam penelitian. Cara yang digunakan untuk memudahkan peneliti untuk menyelesaikan suatu permasalahan dengan mengidentifikasi terlebih dahulu dari suatu permasalahan yang akan diteliti nantinya. Selain itu juga akan ditentukan studi apa saja yang harus dilakukan selama penelitian.

\section{Perumusan Masalah}

Pada tahap ini akan dilakukan perumusan masalah yang akan diupayakan untuk diselesaikan dengan metode-metode tertentu. Karena masalah yang akan berkaitan dengan tujuan penelitian ini sangat penting. Pada tahap ini langkah selanjutnya adalah menentukan penyebab suatu permasalahan yang lebih riil dan sebagai latar belakang dalam penelitian ini.

\section{Penentuan Tujuan Penelitian}

Pada tahap ini akan dilakukan dengan tujuan yang ingin dicapai dalam sebuah penelitian. Karena tujuan penelitian adalah hal-hal yang ingin diidentifikasi dan didasarkan pada perumusan masalah. Dalam tahapan ini tujuan penelitian didapatkan sutu tujuan, yaitu untuk penjadwalan Preventive Maintenance dan untuk meminimalkan biaya kerusakan mesin tersebut.

\section{Studi Literatur}

Studi literatur bertujuan sabagai studi yang dilakukan dengan mempelajari teori-teori sehubungan dengan judul penelitian. Hal ini dilakukan untuk mempermudah peneliti dalam pemecahan masalah yang telah ditentukan sebelumnya. Dalam memperoleh informasi ini yang bersifat konseptual dan berkaitan dengan penelitian ini diperoleh dengan cara membaca dan memahami dari berbagai sumber literatur yang ada, misalnya seperti di buku, jurnal atau dari penelitian yang sudah ada. Teori yang dipelajari dalam penelitian ini adalah definisi perawatan, definisi analisa biaya, metode Markov Chain.

\section{Studi Lapangan}

Studi lapangan dilakukan untuk mengetahui kondisi riil objek penelitian. Studi lapangan dalam penelitian kali ini akan dilakukan pada internal perusahaan dan eksternal perusahaan mencakup pelanggan sesuai dengan batasan penelitian. Pada internal perusahaan akan diidentifikasi upaya apa saja yang sudah dilakukan dalam meningkatkan kinerja mesin. Pada penelitian ini yang dijadikan obyek penelitian adalah di perusahaan PT. Steel Pipe Industry of Indonesia unit 3 yang berlokasi di Surabaya yang memproduksi pipa baja.

\section{Tahap Pengumpulan Data}

Yaitu melakukan pengumpulan data dengan melakukan riset lapangan, suatu cara untuk memperoleh data dengan pengamatan terhadap suatu proyek yang diteliti (teknik observasi dan interview) juga menggunakan metode dokumentasi, teknik pengumpulan data dengan cara menyalin catatan-catatan yang ada dalam perusahaan. Data - data yang dikumpulkan antara lain :

a. Data Primer

Data primer diperoleh dengan melakukan riset lapangan. Riset lapangan (field research) merupakan suatu cara untuk memperoleh data dengan pengamatan terhadap suatu obyek yang diteliti. Kegiatan ini dimaksudkan untuk memperoleh data sebenarnya di perusahaan yang berkaitan dengan penelitian.

Adapun teknik yang digunakan adalah :

1. Observasi

Pengumpulan data dengan melakukan pengamatn aktifitas langsung pada obyek dilapangan.

2. Interview

Pengumpulan data dengan melakukan wawancara / tanya jawab langsung tentang permasalahan yang diteliti. Dalam hal ini yang akan di mintai wawancara adalah pimpinan perusahaan, staff dan karyawan.

b. Data Sekunder

Pada data Sekunder akan diperoleh dengan cara melakukan pencatatan data-data dari dokumen perusahaan dan juga dari studi pustaka yang berhubungan dengan masalah di dalam penelitian ini.

(1) Tinjauan Pustaka

Tinjauan pustaka dalam penelitian akan dilakukan dengan maksud untuk memperoleh data pustaka sebagai narasumber yang dapat dijadikan pedoman didalam memecahkan masalah yang dihadapi oleh perusahaan

(2) Dokumen Perusahaan

Dokumen ini berupa data yang diperoleh atau dikumpulkan dari laporan-laporan tersimpan milik perusahaan.

Data tersebut terdiri dari :

(a) Jenis dan jumlah mesin produksi yang mengalami kerusakan beserta komponen yang menyebabkan kerusakan

(b) Jika mesin yang mempunyai status baik, kerusakan ringan, kerusakan sedang, 
kerusakan berat untuk masing-masing mesin.

(c) Mesin yang mengalami transisi status untuk setiap item.

(d) Waktu pemeliharaan pencegahan.

(e) Waktu pemeliharaan perbaikan.

(f) Data waktu kerusakan dan biaya downtime.

\section{Tahap Analisa dan Pembahasan}

Dalam tahap ini dilakukan analisa dan pembahasan dari tahap pengolahan data. Analisa data merupakan proses lanjutan dari tahap pengolahan data. Hasil dari pengolahan data akan diinterprestasikan lebih rinci. Hasil tersebut dianalisis dan dibahas untuk menjawab permasalahan yang dihadapi dan mendapatkan solusi dari permasalahan penjadwalan perawatan mesin produksi.

\section{Tahap Kesimpulan dan Saran}

Tahap ini merupakan tahap terakhir, hasil dari pengolahan data dan analisa pembahasan akan digunakan untuk menarik kesimpulan agar bisa diperoleh ringkasan jawaban dari perumusan masalah dan tujuan. Selain itu dalam tahap ini peneliti juga dapat memberikan solusi kepada perusahaan terkait dengan penjadwalan perawatan mesin yang diberikan.

\section{HASIL DAN PEMBAHASAN}

Pada penelitian ini ditentukan status, kelas, kondisi mesin, downtime dan biaya yang harus dikeluarkan oleh perusahaan untuk kerusakan mesin Mill 330.

Tabel 1. Klasifikasi Kerusakan Mesin Mill 303

\begin{tabular}{|c|c|c|c|c|}
\hline Status & Kelas & Kondisi mesin & Downtime & Biaya \\
\hline 1 & Baik & $\begin{array}{l}\text { - Mesin berjalan } \\
\text { dengan baik } \\
\text { (normal) } \\
\text { - Tidak mengalami } \\
\text { kerusakan }\end{array}$ & $\begin{array}{l}\text { Sesuai } \\
\text { jadwal PM }\end{array}$ & \\
\hline 2 & Ringan & $\begin{array}{l}\text { - Kotor } \\
\text { - Limit switch } \\
\text { pintu belum } \\
\text { nempel } \\
\text { - Air welding } \\
\text { kurang }\end{array}$ & $\begin{array}{l}<100 \\
\text { menit }\end{array}$ & $\begin{array}{l}<\text { Rp } \\
100 \\
\text { juta }\end{array}$ \\
\hline 3 & Sedang & $\begin{array}{l}\text { - Tidak mau on / } \\
\text { Standby } \\
\text { - Tekanan cooling } \\
\text { tidak normal } \\
\text { - Selang air bocor }\end{array}$ & $\begin{array}{l}<320 \\
\text { menit }\end{array}$ & $\begin{array}{l}>\text { Rp } \\
500 \\
\text { juta }\end{array}$ \\
\hline 4 & Berat & $\begin{array}{l}\text { - Rusak } \\
\text { - Breaker trip } \\
\text { - Tidak berfungsi }\end{array}$ & $\begin{array}{l}>\quad 320 \\
\text { menit }\end{array}$ & $\begin{array}{l}>\text { Rp } \\
500 \\
\text { juta }\end{array}$ \\
\hline
\end{tabular}

Perubahan status mesin Mill 303 dari jenis kerusakan pada mesin Mill 303 pada kondisi sebelumnya yaitu ( status ringan, status sedang, status berat). Pada perubahan status mesin ini didapat dari tabel 2 frekuensi perhitungan jumlah kegiatan maintenance dari perusahaan dan yang diusulkan.

Tabel 2. Probabilitas transisi Kegiatan Maintenance Mesin Mill 303

\begin{tabular}{|c|c|c|c|c|c|c|}
\hline \multicolumn{2}{|c|}{ Status akhir } & $1(j)$ & $2(j)$ & $3(j)$ & $4(j)$ & \multirow{2}{*}{ Jumlah } \\
\cline { 2 - 6 } & Baik & Ringan & Sedang & berat & \\
\hline 1 (i) & Baik & 10 & 0 & 0 & 0 & 10 \\
\hline 3 (i) & Ringan & 13 & 46 & 0 & 0 & 59 \\
\hline 4 (i) & Sedang & 0 & 28 & 50 & 0 & 78 \\
\hline \multicolumn{2}{|c|}{ Jumlah } & 23 & 74 & 52 & 11 & 160 \\
\hline
\end{tabular}

Berikut adalah hasil dari perhitungan untuk menentukan biaya rata-rata perawatan mesin Mill 303.

\section{Menentukan Biaya Rata - rata Perawatan Mesin Mill 303}

Biaya rata-rata perawatan Mesin Mill 303 yang ada di Perusahaan selama 2 tahun.

- Biaya Rata - rata PM (Preventive Maintenance) untuk mesin Mill 303 adalah sebagai berikut:

$$
\frac{\text { a.477.791.192 }}{10}=\text { Rp. } 347.773 .182
$$

Jumlah maintenance PM selama 2 tahun yaitu tahun 2016 dan 2017 adalah 10 kali perawatan.

- Biaya Rata - rata CM (Corrective Maintenanace)

Rp. $\frac{30.099 .611 .299}{150}=$ RP. 200.664.408,-

Jumlah maintenance CM selama 2 tahun yaitu tahun 2016 dan 2017 adalah 139 kali perawatan.

\section{Biaya PM (Preventive Maintenance) dan CM (Corrective Maintenance) di Perusahaan}

Perhitungan biaya Preventive Maintenance dan CM Corrective Maintenance yang ada di Perusahaan berdasarkan pada probabilitas transisi kerusakan mesin Mill 303 PM dan CM yang ada di perusahaan:

Kondisi status ringan pada kerusakan ringan mesin Mill 330 adalah:

$$
\begin{aligned}
= & ((0.09 \times \text { Rp. } 548.437 .272 .,-)+(0.91 \times \text { Rp. } \\
& 548.437 .272,-)) \\
= & \text { Rp. } 548.437 .272
\end{aligned}
$$

Kondisi status sedang pada kerusakan mesin Mill 330 adalah:

$$
\begin{aligned}
= & ((0.30 \times \text { Rp. } 548.437 .272,-)+(0.70 \times \mathrm{Rp} . \\
& 548.437 .272,))
\end{aligned}
$$


$=$ Rp. 548.437 .272

Kondisi status berat pada kerusakan mesin Mill 330 adalah :

$=(0,5 \times \mathrm{Rp} 548.437 .272)+(0,5 \times \mathrm{Rp} 548.437 .272)$

$=$ Rp. 548.437 .272

Biaya PM (Preventive Maintenance) dan CM (Corrective Maintenance) yang disarankan untuk Perusahaan

Pada perhitungan Preventive Maintenance dan Corrective Maintenance didasarkan pada probabilitas transisi mesin Mill 303, hal ini digunakan sebagai usulan ke perusahaan. Berikut adalah perhitungan biaya Preventive Maintenance dan Corrective Maintenance pada mesin Mill 303 dalam kondisi status ringan, sedang dan berat.

- Kondisi status ringan pada kerusakan mesin Mill 330 adalah:

$=((0.03 \times$ Rp. 548.437.272,-) + (0.29 x Rp.

548.437.272,-))

$=$ Rp.175.499.992

- Kondisi status sedang pada kerusakan mesin Mill 330 adalah:

$=((0.13 \times$ Rp. 548.437.272,-) $+(0.31 \times$ Rp.

548.437.272,-))

$=$ Rp. 241.312 .393

- Kondisi status berat pada kerusakan mesin Mill 303 adalah:

$=((0.07 \times$ Rp. 548.437.272,-) $+(0.07 \times$ Rp. 548.437.272,-))

$=$ Rp.76.781.215

Pada tahapan selanjutnya adalah melakukan perhitungan biaya Preventive Maintenance dan Corrective Maintenance pada mesin Mill 303 yang ada di perusahaan, perhitungan yang dilakukan untuk mengetahui perubahan biaya Preventive Maintenance dan Corrective Maintenance yang mengalami penurunan diantara keduanya. Berikut adalah hasil perhitungan dari perubahan biaya Preventive Maintenance dan Corrective Maintenance yang ada di perusahaan adalah sebagai berikut:

Tabel 3. Biaya Preventive Maintenance dan Corrective Maintenance di Perusahaan

\begin{tabular}{|c|c|}
\hline $\begin{array}{c}\text { Status Kerusakan } \\
\text { mesin }\end{array}$ & $\begin{array}{c}\text { PT. Steel Pipe Industry Of } \\
\text { Indonesia }\end{array}$ \\
\hline Ringan & Rp. 3.477.731.820 \\
\hline Sedang & Rp. 3.477.731.820 \\
\hline Berat & Rp. 3.477.731.820 \\
\hline
\end{tabular}

Dari tabel menunjukan bahwa status kerusakan mesin dengan status ringan, sedang dan berat adalah Rp. 3.477.731.820 dengan demikian dapat diartikan bahwa perusahaan setiap tahunnya mengeluarkan total biaya preventive maintenance dan corrective maintenance adalah sebesar Rp. 10.433.195.460.

Pada tabel 4 berikut adalah biaya Preventive Maintenance dan Corrective Maintenance yang akan diusulkan ke perusahaan, dari tabel menunjukkan bahwa kerusakan mesin Mill 303 dengan status ringan mempunyai biaya sebesar Rp. 175.499.992. Kerusakan mesin Mill 303 dengan status sedang adalah sebesar Rp. 241.312.393, dan kerusakan mesin Mill 330 dengan status berat adalah Rp. 76.781.215.

Tabel 4. Biaya Preventive Maintenance dan Corrective Maintenance Usulan ke Perusahaan

\begin{tabular}{|c|c|}
\hline $\begin{array}{c}\text { Status } \\
\text { Kerusakan } \\
\text { mesin }\end{array}$ & $\begin{array}{c}\text { Biaya PM dan CM yang di } \\
\text { usulkan }\end{array}$ \\
\cline { 2 - 2 } & Hasil usulan \\
\hline Ringan & Rp. 175.499 .992 \\
\hline Sedang & Rp. 241.312 .393 \\
\hline Berat & Rp. 76.781.215 \\
\hline
\end{tabular}

Biaya yang akan diusulkan ke perusahaan pada status ringan, sedang dan berat adalah total adalah Rp. 493.593.600. Dari biaya tersebut dilihat pada status kerusakan mesin yang sedang yang membutuhkan biaya yang besar yaitu Rp. 241.312.393, hal ini menunjukkan bahwa biaya preventive maintenance dan corrective maintenance sehingga akan lebih sedikit dibandingkan dengan status kerusakan yang lain.

Tabel 5. Selisih Biaya Preventive Maintenance dan Corrective Maintenance

\begin{tabular}{|c|c|c|c|}
\hline \multirow{2}{*}{$\begin{array}{c}\text { Status } \\
\text { Kerusakan } \\
\text { mesin }\end{array}$} & \multicolumn{2}{|c|}{$\begin{array}{c}\text { Biaya Preventive Maintenance } \\
\text { dan Corrective Maintenance }\end{array}$} & \multirow{2}{*}{$\begin{array}{c}\text { Selisih Biaya } \\
\text { PM dan CM } \\
\text { yang di } \\
\text { usulkan }\end{array}$} \\
\hline & $\begin{array}{l}\text { PT. Steel Pipe } \\
\text { Industry Of } \\
\text { Indonesia }\end{array}$ & Hasil usulan & \\
\hline Ringan & 548.437 .272 & 175.499 .992 & $372,937,335$ \\
\hline Sedang & 548.437 .272 & 241.312 .393 & 237.834 .661 \\
\hline Berat & 548.437 .272 & 76.781 .215 & $471,656,042$ \\
\hline
\end{tabular}

Pada tabel diatas menunjukan bahwa biaya masing-masing perawatan Preventive Maintenance dan Corrective Maintenance pada status ringan, status sedang dan status berat adalah sebesar Rp. 548.437.272. Sedangkan dari hasil perhitungan biaya Preventive Maintenance dan Corrective Maintenance yang akan diusulkan ke perusahaan adalah untuk status kerusakan ringan adalah $\mathrm{Rp}$. 175.499.992, sedangnya status kerusakan mesin dikatakan sedang adalah sebesar Rp. 241.312.393, sedangkan status kerusakan mesin dikatakan berat adalah sebesar Rp. 76.781.215. 
Dari data di tabel menunjukkan bahwa biaya Preventive Maintenance dan Corrective Maintenance yang membutuhkan biaya terbesar adalah pada status sedang pada kerusakan mesin Mill 303 hal ini menunjukkan bahwa pada status kerusakan sedang harus dilakukan perawataran sesuai dengan jadwal yang ditentukan sehingga dapat mengurangi biaya perbaikan.

Berikut adalah total biaya Preventive Maintenance 2017 dan 2018 yang ada di perusahaan, dimana dalam biaya tersebut didapatkan dari total waktu Preventive Maintenance dan biaya yang dikeluarkan oleh perusahaan.

Tabel 6. Total Waktu dan Biaya Preventive Maintenance 2017 dan 2018 di Perusahaan

\begin{tabular}{|c|c|c|c|}
\hline \multirow{2}{*}{$\begin{array}{c}\text { Kondisi } \\
\text { Kerusa } \\
- \\
\text { kan }\end{array}$} & \multicolumn{3}{|c|}{ Waktu Pemeliharaan (menit) } \\
\hline & $\begin{array}{l}\text { PT. Steel Pipe } \\
\text { Industry Of } \\
\text { Indonesia }\end{array}$ & $\begin{array}{c}\text { Perusa- } \\
\text { haan }\end{array}$ & $\begin{array}{c}\text { Total } \\
\text { Waktu } \\
\text { PM }\end{array}$ \\
\hline Ringan & Rp. 3.477.731.820 & 2028 & 1023 \\
\hline Sedang & Rp. 3.477.731.820 & 2028 & 1407 \\
\hline Berat & Rp. 3.477.731.820 & 2028 & 447 \\
\hline
\end{tabular}

Dari tabel diatas menunjukkan bahwa kondisi kerusakan mesin status sedang memerlukan waktu yang lama untuk preventive maintenance dari mesin Mill 303 yang ada di perusahaan pada saat ini adalah sebesar dengan biaya Rp. 3.477.731.820. Berikut adalah total waktu dan biaya preventive maintenance yang diusulkan perusahaan. Dalam tabel didapat total waktu Preventive Maintenance dari kerusakan mesin Mill 303 dengan status sedang adalah 1407 dengan biaya sebesar Rp. 2.413.123.930. Hal ini menunjukkan bahwa total biaya yang diusulkan berdasarkan perhitungan preventive maintenance lebih kecil daripada biaya yang dikeluarkan oleh di perusahaan.

Tabel 7. Total Waktu dan Biaya Preventive Maintenance 2017 dan 2018 Usulan ke Perusahaan

\begin{tabular}{|c|c|c|c|}
\hline \multirow{2}{*}{$\begin{array}{c}\text { Kondisi } \\
\text { Kerusa- } \\
\text { kan }\end{array}$} & \multicolumn{3}{|c|}{ Waktu Pemeliharaan (menit) } \\
\hline & $\begin{array}{l}\text { Hasil usulan } \\
\text { (RP) }\end{array}$ & $\begin{array}{c}\text { Perusa- } \\
\text { haan }\end{array}$ & $\begin{array}{c}\text { Total } \\
\text { Waktu PM }\end{array}$ \\
\hline Ringan & Rp. 1.754.999.222 & 2028 & 1023 \\
\hline Sedang & Rp. 2.413.123.930 & 2028 & 1407 \\
\hline Berat & Rp. 767.812159 & 2028 & 447 \\
\hline
\end{tabular}

Dari perhitungan yang dilakukan maka dapat dikatakan bahwa pemeliharaan mesin Mill 303 melakukan pemeliharaan sebanyak 10 kali selama 2 tahun dalam jangka waktu per 2,4 bulan akan membutuhkan waktu :

- Mesin dalam kondisi rusak ringan selama 1023 menit dengan biaya sebesar Rp 1.754.999.222

- Mesin dalam kondisi rusak sedang selama 1407 menit dengan biaya sebesar Rp 2.413.123.930

- Mesin dalam kondisi kerusakan berat selama 447 menit dengan biaya sebesar Rp 767.812159
Berikut adalah periode waktu preventive maintenance setiap tahun yang ada di perusahaan, pada tabel terlihat bahwa kondisi kerusakan status sedang membutuhkan preventive Maintenance untuk setiap 1 tahun di perusahaan selama 2028 menit dan membutuhkan waktu 2,7 bulan.

Tabel 8. Periode Waktu Preventive Maintenance setiap 1 Tahun di Perusahaan

\begin{tabular}{|c|c|c|c|}
\hline $\begin{array}{c}\text { Kondisi } \\
\text { Kerusakan }\end{array}$ & $\begin{array}{c}\text { Preventive } \\
\text { Maintenance (PT. } \\
\text { Steel Pipe Industry } \\
\text { Of Indonesia)(menit) }\end{array}$ & $\begin{array}{c}\text { Jumlah } \\
\text { (bulan/ } \\
\text { tahun) }\end{array}$ & Bulan \\
\hline Ringan & 2028 & 12 & 1.9 \\
\hline Sedang & 2028 & 12 & 2.7 \\
\hline Berat & 2028 & 12 & 0.4 \\
\hline
\end{tabular}

Berikut adalah periode waktu preventive maintenance setiap tahun yang diusulkan ke perusahaan, pada tabel terlihat bahwa kondisi kerusakan status sedang selama 460 menit dan membutuhkan 2,7 bulan.

Hal ini dapat berguna bagi perusahaan untuk dapat memberikan biaya yang lebih rendah dibandingkan dengan prenventive maintenance sebelumnya

Tabel 9. Periode Waktu

Preventive Maintenance setiap 1 Tahun Usulan ke Perusahaan

\begin{tabular}{|c|c|c|c|}
\hline $\begin{array}{c}\text { Kondisi } \\
\text { Kerusakan }\end{array}$ & $\begin{array}{c}\text { Preventive } \\
\text { Maintenance } \\
\text { (hasil usulan) } \\
\text { (menit) }\end{array}$ & $\begin{array}{c}\text { Jumlah } \\
\text { (bulan/ } \\
\text { tahun) }\end{array}$ & Bulan \\
\hline Ringan & 327 & 12 & 1.9 \\
\hline Sedang & 460 & 12 & 2.7 \\
\hline Berat & 63 & 12 & 0.4 \\
\hline
\end{tabular}

\section{PENUTUP}

Berdasarkan analisa yang sudah dilakukan maka dapat disimpulkan sebagai berikut :

1. Perencanaan perawatan mesin Mill 303 pada kondisi mesin dalam kerusakan sedang dan berat membutuhkan rata-rata biaya pemeliharaan perusahaan sebesar Rp. 548.437.272. Biaya pemeliharaan usulan mesin Mill 303 pada kondisi kerusakan ringan adalah Rp.175.499.992,- dengan selisih dari biaya pemeliharaan perusahan sebesar Rp 372,937,335 (68\%). Pada kondisi kerusakan sedang adalah Rp.241.312.393,- dengan selisih dari biaya pemeliharaan perusahan sebesar Rp 307.124,864 (56\%). Pada kondisi kerusakan berat adalah Rp.76.781.215,- dengan selisih dari biaya pemeliharaan perusahan sebesar Rp $471,656,042$ (86\%). Selisih antara biaya ratarata perawatan perusahaan dan biaya yang di 
usulan ke perusahaan yang bernilai besar akan acuan untuk perusahan dalam melakukan perawatan pada periode berikutnya.

2. Berdasarkan hasil dari perhitungan markov chain dapat dijadwalkan bahwa Preventive Maintenance yang diusulkan yaitu setiap 0,4 bulan selama 1 tahun, sedangkan schedule perawatan usulan dapat di asumsikan tersedianya spare part pada saat dibutuhkan.

\section{DAFTAR PUSTAKA}

Anshori, Nachnul, Mustajib, M. I. (2013) Sistem Perawatan Terpadu (Integrated Maintenance System). Pertama. Yogyakarta, Graha Ilmu.

Anshori, N. \& M. I. . (2013) Sistem Perawatan Terpadu. Yogyakarta: Graha Ilmu. Yogyakarta: Graha Ilmu.

Handayani, P. Dan T. Y. (2018) Teknik Pemeliharaan Dan Perbaikan Sistem Elektronika. Jilid 1. Jakarta: Direktorat Pembinaan Sekolah Menengah Kejuruan, Direktorat Jenderal Manajemen Pendidikan Dasar Dan Menengah. Departemen Pendidikan Nasional.

Hartono Dan Mas'udin (2002) 'Perencanaan Perawatan Mesin Dengan Menggunakan Metode Markov Chain Guna Menurunkan Biaya Perawatan.', Jurnal Optimum., Vol. 3. No, P. Hal 173-184.

Ilma, F. (2012) Perencanaan Pemeliharaan Mesin Dengan Menggunakan Metode Markov Chain Untuk Mengurangi Biaya Pemeliharaan Di Pt. Philips Indonesia. Surabaya. Available At: Http://Eprints.Upnjatim.Ac.Id/Id/Eprint/388 5.
Kurniawan, F. (2013) Manajemen Perawatan Industri. Yogyakarta: Graha Ilmu.

Kusuma, F. (2018) 'Penjadwalan Perawatan Mesin Di Industri Menggunakan Metode Markov Chain'. Available At: Http://Repository.Unpas.Ac.Id/Id/Eprint/325 11 (Accessed: 10 April 2018).

Manzini, R. Et Al. (2010) Maintenance For Industrial Systems. London: Springe.

Pudji, E. And Ilma, F. (2012) 'Perencanaan Pemeliharaan Mesin Dengan Menggunakan Metode', (November).

Riyardi, A. (2011) 'Kapasitas Sumber Daya Manusia', 4(September), Pp. 91-101.

Rochmoeljati, R (2014) Perencanaan Perawatan Mesin Menggunakan Metode Markov Chain Untuk Meminimumkan Biaya Perawatan Rr.Rochmoeljati', Pp. 63-76.

Sudrajat, A. (2011) Pedoman Praktis Manajemen Perawatan Mesin Industri. Bandung: Retika Aditama.

Suparjo (2014) 'Mencapai Ekspektasi Pendapatan Maksimum Dengan Pendekatan Rantai Markov Di Cv . Alextra Travel', Pp. 612-618.

Toyiba, R. (2012) Analisis Perencanaan Pemeliharaan Mesin Power Pack Plant Dengan Menggunakan Metode Markov Chain Untuk Meminimumkan Biaya Pemeliharaan Di Pt. Laser Jaya Sakti Gempol - Pasuruan. Surabaya. 